\title{
Raised parathyroid hormone levels in the milk alkali syndrome: an appropriate response?
}

\author{
David W. Bullimore and Krzysztof J. Miloszewski
}

St. James's Hospital, Leeds LS9 7TF, UK.

\begin{abstract}
Summary: A case of the 'milk alkali syndrome' associated with grossly elevated levels of amino terminal parathyroid hormone is described. The hypercalcaemia (calcium $4.09 \mathrm{mmol} / \mathrm{l}$ ) and hyperparathyroidism settled on conservative measures. Factors in the milk alkali syndrome which might stimulate the release of parathyroid hormone include parathyroid gland hyperplasia secondary to suppression of ionized calcium, alteration in sensitivity of calcium receptors on the cells of the parathyroid glands, the stimulation of an intermittent alkaline tide in the blood and the high intake of phosphate and bicarbonate. We suggest that high levels of parathyroid hormone in the milk alkali syndrome may be appropriate rather than paradoxical.
\end{abstract}

\section{Introduction}

The Sippy diet for the management of peptic ulceration involved the consumption of large amounts of calcium and absorbable alkali. ${ }^{1}$ Soon after its introduction toxic complications were noted. ${ }^{2}$ In 1949 Burnett ${ }^{3}$ described the chronic form of toxicity characterized by hypercalcaemia, alkalosis and renal dysfunction in subjects with a prolonged and excessive intake of milk and absorbable alkali. The condition has become known as the milk alkali syndrome or Burnett's syndrome.

Several cases have been reported in association with primary hyperparathyroidism. ${ }^{4-6}$ The association has been considered to be either coincidental or representing cases of primary hyperparathyroidism in subjects taking large quantities of calcium and absorbable alkali for relief of dyspeptic symptoms, peptic ulceration occurring more commonly in subjects with hyperparathyroidism. ${ }^{7}$

The case described is of a woman with the milk alkali syndrome and raised levels of parathyroid hormone, in the presence of marked hypercalcaemia, suggestive of hyperparathyroidism. The hypercalcaemia resolved rapidly (days) and the hyperparathyroidism gradually (months) on rehydration and cessation of excessive intake of calcium and alkali. The possible causes of the apparently paradoxical elevation of parathyroid hormone are discussed.

Correspondence: D.W. Bullimore, M.D.

Accepted: 24 March 1987

\section{Case report}

A 35 year old woman presented with chronic constipation, anorexia and a 6 week history of nausea and vomiting. Following a Heller's operation for achalasia at age 13 and two subsequent antireflux procedures she had persistent symptoms of oesophageal reflux. Her typical daily calcium intake was $6.5 \mathrm{~g}$ (normal $0.6 \mathrm{~g}$ ) in the form of 4 pints of milk, 12 'Rennies', a proprietary antacid containing calcium and magnesium carbonate, and 'Complan', a food supplement, plus large amounts of absorbable alkali. Investigations showed a hypochloraemic alkalosis, marked hypercalcaemia and evidence of renal dysfunction. Calcium $4.09 \mathrm{mmol} / 1$ (normal 2.20-2.60); calcium (alb adj) $3.84 \mathrm{mmol} / 1$; chloride $85 \mathrm{mmol} / 1$ (normal 98 109); bicarbonate $38 \mathrm{mmol} / 1$ (normal 20-28); urea $24 \mathrm{mmol} / 1$ (normal 2.2-7.7); creatinine $290 \mu \mathrm{mol} / 1$ (normal 45-120); phosphate $1.07 \mathrm{mmol} / 1$ (normal 0.8-1.3). Blood $\mathrm{pH}$ was 7.55 (7.36-7.44) and urinary $\mathrm{pH}$ was 8 . A diagnosis of the 'milk alkali syndrome' was made.

With rehydration and a low calcium diet the urea and bicarbonate became normal within a few days and by nine days the serum calcium, corrected for albumin, fell to within the normal range. With a corrected calcium of $2.59 \mathrm{mmol} / \mathrm{l}$, phosphate of $1.17 \mathrm{mmol} / \mathrm{l}$ and creatinine of $137 \mu \mathrm{mol} / \mathrm{l}$ urinary excretion studies were undertaken. Results (normal range) were as follows: calcium/creatinine ratio $1.17(0.10-0.45)$, calcium excretion $0.16 \mathrm{mmol} / 1$ of glomerular filtrate $(0.01-$ 0.05 ), phosphate excretion $0.18 \mathrm{mmol} / 1$ of glomerular filtrate $(0.05-0.22), \mathrm{TmP} / \mathrm{GFR} 0.99(0.71-1.36){ }^{8}$ These results suggest a degree of renal resistance to the action of parathyroid hormone. Other studies 
included normal thyroid function tests, serum cortisol, serum gastrin, serum magnesium and ultrafiltrable magnesium. Endoscopy with oesophageal biopsy and 24-hour oesophageal $\mathrm{pH}$ monitoring confirmed the presence of reflux oesophagitis and the absence of duodenal and gastric ulceration. A skeletal survey showed no evidence of hyperparathyroidism or metastatic calcification and thallium scintigraphy and computerized axial tomography showed no parathyroid adenoma. However, amino terminal parathyroid hormone was initially elevated at $1100 \mathrm{pg} / \mathrm{ml}$ (normal $<120$ ) when the calcium was $3.18 \mathrm{mmol} / \mathrm{l}$ (albumin $38 \mathrm{~g} / \mathrm{l})$. This level of parathyroid hormone is within the range $(100-1350 \mathrm{pg} / \mathrm{ml})$ normally seen in primary hyperparathyroidism. ${ }^{9}$

At 20 weeks the corrected calcium was $2.44 \mathrm{mmol} / \mathrm{l}$ and, using a calcium ion specific electrode, the ionized calcium was $1.27 \mathrm{mmol} / 1$ (normal range 1.15 $1.27 \mathrm{mmol} / \mathrm{l})$. The amino terminal parathyroid hormone remained elevated at $1000 \mathrm{pg} / \mathrm{ml}$.

Alkaline phosphatase levels varied between 9 and $16 \mathrm{KA}$ units/dl (normal range 3-13 KA units/dl) suggesting a degree of increased bone turnover in response to the high levels of parathyroid hormone.

By 38 weeks the calcium had fallen to the midnormal range at $2.35 \mathrm{mmol} / \mathrm{l}$ as had the corrected calcium $(2.29 \mathrm{mmol} / \mathrm{l})$ and the ionized calcium $(1.22 \mathrm{mmol} / \mathrm{l})$. The amino terminal parathyroid hormone also fell to the mid-normal range. TmP/GFR (0.91), calcium excretion $(0.02 \mathrm{mmol} / 1$ of glomerular filtrate) and phosphate excretion $(0.13 \mathrm{mmol} / 1$ of glomerular filtrate) were normal.

\section{Discussion}

Hyperparathyroidism has been reported in association with the milk alkali syndrome and exploration of the neck undertaken with removal of an enlarged parathyroid gland. ${ }^{46}$ The differentiation between the two conditions has sometimes proven difficult. ${ }^{10,11}$ It would be expected that the development of assays for parathyroid hormone would allow a clear separation of cases of milk alkali syndrome from primary hyperparathyroidism. In the milk alkali syndrome the elevated calcium should be associated with suppression of parathyroid hormone. In hyperparathyroidism the parathyroid hormone should be elevated or inappropriately high in the face of the hypercalcaemia. However, the separation has not proven to be so clear cut. Elevated parathyroid hormone levels have occasionally been noted in the milk alkali syndrome ${ }^{10-}$ ${ }_{12}$ and have led to confusion with primary hyperparathyroidism. In some cases surgical exploration of the parathyroid glands has been undertaken and no abnormality found. ${ }^{11}$ In other cases the elevated parathyroid hormone levels have resolved over a number of months, ${ }^{10-12}$ Unfortunately the assay used has sometimes been a C-terminal parathyroid hor- $\mathbb{\otimes}$ mone assay which can give falsely elevated values in $\mathrm{C}$ renal failure as the biologically inactive C-terminal $\stackrel{\Rightarrow}{\Rightarrow}$ fragments are excreted via the kidney. ${ }^{13}$

There are a number of factors in the milk alkali syndrome which might stimulate parathyroid hormone release: (1) The milk alkali syndrome is a chronic $\frac{D}{\partial}$ condition and the severe hypercalcaemia and marked $\stackrel{\mathbb{\Phi}}{\circ}$ renal dysfunction seen at presentation in this case reflect an acute deterioration of a chronic state. At presentation the ionized calcium, given the extreme elevation in the total calcium, would not be depressed despite the marked alkalosis. ${ }^{14}$ However, for much of $\stackrel{\rho}{\omega}$ the course of the milk alkali syndrome a chronic $\vec{C}$ alkalosis could produce a low ionized calcium even 3 though the total calcium might be normal or slightly $\dot{\sigma}$ increased. Thus tetany is a recognized feature of the excessive oral intake of absorbable alkali. ${ }^{2}$ A chronic $\vec{\omega}$ low ionized calcium would result in parathyroid gland stimulation and resultant hyperplasia analogous to the secondary hyperparathyroidism seen as a response to 은 a low serum calcium in renal failure. ${ }^{15}$ Following correction of the alkalosis the hyperplastic para- $\mathcal{D}$ thyroid glands could continue to secrete an inap- $\frac{\mathbb{D}}{D}$ propriate amount of parathyroid hormone as parathyroid cells are not totally suppressible by serum calcium levels within the normal range. ${ }^{16}$ This woulg explain the delay in normalization of the parathyroj $\overrightarrow{0}$ hormone seen in this case. An additional factor which could stimulate parathyroid gland hyperplasia is tha the interaction of calcium with protein receptors on the parathyroid cells is likely to be a pH dependent process, as is the binding of calcium to other proteins. A chronic alkalosis might prevent the parathyroid cell from detecting the ionzied calcium as efficiently as normal and adapting its level of secretion appropriately.

(2) Intake of calcium-containing absorbable alkalis is followed by neutralization of gastric acid and systemic alkalosis. This systemic alkalosis can produce a decrease of ionized calcium which, while still within the normal range, produces a doubling of parathyroid hormone secretion. ${ }^{17,18}$ Such swings in ionized calcium taking place several times per day in response to frequent self-medication with absorbable alkali could produce marked parathyroid gland stimulation with- 은 out ionized calcium or total serum calcium being $D$ outside the normal range. Parathyroid gland hyperplasia is commonly seen in Wermer's syndrome (multi- N ple endocrine adenomatosis type I). ${ }^{19,20}$ The increased gastric acid secretion secondary to the presence of $\tilde{D}$ non-beta cell tumours of the pancreas in this syndrome $\underset{\omega}{N}$ can also produce an alkaline tide in the blood. ${ }^{18} \mathrm{~A}$ similar systemic alkalosis is seen in the Zollinger- $O$ Ellison syndrome. Elevated parathyroid hormone $\overparen{\Phi}$ levels have been found in the Zollinger-Ellison syn- $\stackrel{\infty}{+}$ 
drome and these elevated levels have returned to normal following resection of the non-beta cell gastrin secreting pancreatic tumours. ${ }^{21}$

(3) Other recognized effects of parathyroid hormone include promotion of bicarbonaturia, ${ }^{22}$ which would tend to limit any alkalosis present, and phosphate excretion. Phosphate intake is frequently high in these subjects due to their high milk intake although the syndrome may occur even when excessive amounts of milk are not consumed. ${ }^{10}$ The phosphatiuric effect of parathyroid hormone promotes excretion of excess phosphate. ${ }^{22}$

Thus, while parathyroid gland stimulation in the milk alkali syndrome at first appears paradoxical there are a number of factors present which make it likely to occur.

It is interesting to note that in several of the reported cases of hyperparathyroidism and milk alkali syndrome occurring together the findings at surgery were of hyperplasia of several parathyroid glands or aden-

\section{References}

1. Sippy, B.W. Gastric and duodenal ulcer; medical cure by an efficient removal of gastric juice corrosion. JAMA 1915, 64: 1625-1630.

2. Hardt, L.L. \& Rivers, A.B. Toxic manifestations following the alkaline treatment of peptic ulcer. Arch Intern Med 1923, 31: 171-180.

3. Burnett, C.H., Commons, R.R., Albright, F. \& Howard, J.E. Hypercalcaemia without hypercalcuria or hypophosphataemia, calcinosis and renal insufficiency. A syndrome following prolonged intake of milk and alkali. N Engl J Med 1949, 240: 787-794.

4. Carpenter, H.M. \& Paulter, E.E. Hyperparathyroidism with renal insufficiency. Report of a case confused with the 'Burnett Syndrome'. $N$ Engl J Med 1954, 250: 453-456.

5. Kyle, L.H. Differentiation of hyperparathyroidism and the milk-alkali (Burnett) syndrome. $N$ Engl J Med 1954, 251: $1035-1040$.

6. Atlas, D.H., Gaberman, P. \& Eisenberg, H.L. Syndrome of masked hyperparathyroidism. Ann Intern Med 1956, 44: 1195-1210.

7. Barreras, R.F. Calcium and gastric secretion. Gastroenterology 1973, 64: 1168-1184.

8. Nordin, B.E.C. Diagnostic procedures in disorders of calcium metabolism. Clin Endocrinol 1978, 8: 55-67.

9. Papapoulos, S.E., Manning, R.M., Hendy, G.N., Lewin, I.G. \& O'Riordan, J.L.H. Studies of circulating parathyroid hormone in man using a homologous aminoterminal specific immunoradiometric assay. Clin Endocrinol 1980, 13: 57-67.

10. Frame, B., Jackson, G.M., Kleerekoper, M., Rao, D.S., DeLorenzo, A.J.D. \& Garcia, M. Acute severe hypercalcaemia a la Munchausen. Am J Med 1981, 70: 316-319.

11. Carroll, P.R. \& Clark, O.H. Milk alkali syndrome. Does it exist and can it be differentiated from primary hyperparathyroidism? Ann Surg 1983, 197: 427-433. oma formation plus hyperplasia rather than solitary adenoma formation with suppression of the other parathyroid glands, ${ }^{4,6,23,24}$ We suggest that these cases may develop as a result of chronic parathyroid stimulation as discussed above and that cases of hyperplasia alone may resolve spontaneously over a number of months without recourse to surgery.

The original paper by Burnett ${ }^{3}$ over 35 years ago noted in Case 4 that there was 'parathyroid hyperplasia of the chief and oxyphil cell variety thought to be characteristic of secondary hyperparathyroidism'. We suggest that this description may well have been entirely appropriate.

\section{Acknowledgements}

We thank Dr B. Payne and Dr E. Will for helpful discussion, Dr I. Gunn for measurements of ionized calcium and the Supra-Regional Assay Service at the Middlesex Hospital, London for assays of amino terminal parathyroid hormone.

12. Schuman, C.A. \& Jones, H.W. The "milk-alkali" syndrome: Two case reports with discussion of pathogenesis. $Q J$ Med 1985, 55: 119-126.

13. Scott, D.P., Teasdale, P.R. \& Swaminathan, R. Value of measuring C-terminal parathyrin in differential diagnosis of hypercalcemia. Clin Chem 1985, 31: 1838 - 1840.

14. Marshall, R.W. \& Hodgkinson, A. Calculation of plasma ionised calcium from total calcium, proteins and pH: comparison with measured values. Clin Chim Acta 1983, 127: 305-310.

15. Chatterjee, S.N., Friedler, R.M. \& Berne, T.V. The high incidence of persistent secondary hyperparathyroidism after renal homotransplantation. Surg Gynecol Obstet 1976, 143: 440-442.

16. Parfitt, A.M. Hypercalcemic hyperparathyroidism following renal transplantation: differential diagnosis, management and implications for cell population control in the parathyroid gland. Mineral Electrolyte Metab 1982, 8: $92-112$.

17. Kaplan, E.L., Hill, B.J., Locke, S. \& Peskin, G.W. Acidbase balance and parathyroid function: metabolic alkalosis and hyperparathyroidism. Surgery 1971, 70: 198-204.

18. Kaplan, E.L., Peskin, G.W., Deveney, C., Way, L. \& Jaffe, B. Ulcer disease, metabolic alkalosis and hyperparathyroidism: a mechanism of interrelationship? Ann Surg 1974, 180: 549-557.

19. Newsome, H.H. Multiple endocrine adenomatosis. Surg Clin N Am 1974, 54: 387-393.

20. Wermer, $P$. Endocrine adenomatosis and peptic ulcer in a large kindred. Am J Med 1963, 35: 205-212.

21. Jaffe, B.M., Peskin, G.W. \& Kaplan, E.L. Serum levels of parathyroid hormone in the Zollinger-Ellison syndrome. Surgery 1973, 74: 621-625.

22. DeWardener, H.E. In The Kidney. An Outline of Normal and Abnormal Function, fifth edition. Churchill Livingstone, London, 1985, pp 88 and 105. 
23. Wermer, P., Kuschner, M. \& Riley, E.A. Reversible metastatic calcification associated with excessive milk and alkali intake. Am J Med 1953, 14: 108-115.
24. Dufault, F.X. \& Tobias, G.J. Potentially reversible renal failure following excessive calcium and alkali intake in $\mathbb{D}$ peptic ulcer therapy. Am J Med 1954, 16: 231-236. 